\title{
Discussion on flipped classroom and its application of college English teaching
}

\author{
Yan Han \\ Zhejiang Technical Institute of Economics, Hangzhou Zhejiang, 310018, China
}

\begin{abstract}
Keywords: Flipped classroom, College English teaching, Teaching model, Teaching informatization, Feasibility.
\end{abstract}

\begin{abstract}
With the deepening of Chinese educational reform, flipped classroom has been popular in Chinese educational circle and been gradually applied into Chinese educational practice. Flipped classroom is originated from US, with the application theory of constructivism to combine with modern informatization technology in novelty teaching method as one of the most popular teaching methods. This paper has elaborated related theories of flipped classroom and analyzed the feasibility of flipped classroom in college English teaching, and then proposed some suggestions.
\end{abstract}

\section{Introduction}

As the technological development change quickly, educational development continues innovation and educational model reform is getting profound. Chinese educational model is changing from the traditional exam-oriented education to quality-oriented education, and vigorously introducing advanced scientific technology to improve teaching quality. In 2012, Chinese Ministry of Education has issued "Ten-year development planning on education informatization (2011-2020)", which has provided policy support for Chinese educational reform, and indicated the reform direction innovation and introduction of international advanced teaching principles.

In college education, the courses of college English is a critical course, as well as the public basic education course, which is firstly used by many advanced educational models to play an important role in Chinese educational reform. Therefore, it is necessary to strengthen the teaching quality of college English course and improve college students' English so as to make Chinese college English education to connect with the world.

Currently, in international education circle, flipped classroom education model has been well received by many education workers. The model is originated from US, hugely different with traditional educational model, to significantly improve teaching quality. Therefore, Chinese educational reform can consider introducing the flipped classroom teaching model. Of course, Chinese information science technology is developing rapidly and network information is widely applied into education and teaching, which has provide convenient condition for the introduction and promotion of flipped classroom and create good chances. Because of educational informatization, flipped classroom can be the new direction of Chinese educational reform. Flipped classroom is the fighting innovation of Chinese traditional educational model to break through the limitation of traditional educational model. It has many advantages compared with Chinese traditional teaching model. Introduction to Chinese college English teaching can greatly improve the teaching quality of Chinese college English education and deepen the teaching reform of college English, and improve the teaching quality and college students' English level from five aspects of English listening, speaking, reading, writing and translation. 


\section{Related concepts and developmental application of flipped classroom}

What is flipped classroom? It must be defined from two aspects: the time procedure and the process of learning essence. It can be called flipped class or reversed class, FCM for short in English. In FCM model, teachers will combine the difficulties and key points of related basic knowledge to make teaching videos for instruction; students can watch the teaching videos made by teachers after class for independent study, and students are require for online tests for better knowledge absorption and application. Then they will communicate and share issues when watching teaching videos with teachers or classmates in the next class to settle down problems together and digest to improve learning quality and efficiency.

Theory of FCM was proposed by Sylvanus Thayer of West Point who has innovated the traditional teaching model by sending teaching materials to students before classes so that they could preview firstly and then record the difficulties in the preview process, and then communicate with teachers and classmates in next formal classes for group discussion to finally solve confusions.

\section{Feasiblity analysis of introducing FCM into college English teaching}

\section{Difficulties existing in current college English teaching}

Currently, college English teaching is without academic pressure compared with middle and senior English teaching so as to reduce students' pressure. But some colleges set CET4 and CET 6 as students' learning objective. English course is students' major course so it must be reformed. Students must own solid English foundation: vocabularies, grammar, reading ability and other basic knowledge. Only owning these basic knowledge can they make good listening and speaking training, and it requires for students to conduct through learning in good English language environment.

The time of college English teaching will be limited by teaching time arrangement, and the learning site and teaching materials will also be limited. Teachers cannot form good learning English environment. These issues will make the teaching quality cannot be improved. Therefore, teachers cannot correct and guide the issues existing in students' pronunciation. They only blindly study in English course without the chance for application. In the long term, students will lose the interest to learn English and even resist to learn English, which will finally influence the teaching quality of college English course.

\section{Advantages of introducing FCM into college English teaching practice}

\section{Flipped classroom uses the teaching method of "learning first and teaching later"}

Flipped classroom uses the teaching method of "learning first and teaching later", which can improve students' independent learning ability. Eric Mazur's theory thinks that the whole learning process is the process of knowledge transmission and knowledge internalization. But traditional teaching model focuses only knowledge transmission and knowledge internalization in class. Teachers only arrange related schoolwork and students complete for knowledge internalization. In this process, once students meet problems, they cannot ask for help from teachers and classmates in time, which will causes serious influence for the process of knowledge internalization. FCM is to flip the two processes of knowledge transmission and knowledge internalization. The process of knowledge transmission is conducted after class or at home, and the process of knowledge internalization is conducted in the class, i.e. to innovate traditional teaching model in time and dimension so as to improve teaching quality. The knowledge internalization in flipped class teaching mode is conducted under the company of teachers and classmates, to propose problems and solve timely and during the process students can truly digest and absorb knowledge in the process of knowledge internalization to greatly improve classroom teaching quality. This is the largest advantages of FCM compared with traditional teaching model. 
College English teachers can use FCM for instruction by making teaching key points and difficulties into teaching videos lasting 15 to $20 \mathrm{mins}$, in which there is no figure of teachers but the instruction and transmission of knowledge to prevent students distracting from focusing teachers' dressing and other information or influencing their learning quality. Teachers can add cartoon, fun stories and quizzes and other interesting procedures when making teaching videos so as to help students learn in funny classroom and get rid of traditional boring learning environment and increase their learning interests. During watching teaching videos, teacher can play the important knowledge points repeatedly and decide video playing based on students' practical learning condition. This is the process of knowledge transmission in traditional teaching model which can greatly save the time of knowledge transmission and improve students' learning efficiency and teachers' teaching quality.

Teachers should pay attention to improving the activity quality in teaching classroom after flipping and teaching activities must set improving students' independent learning ability as the precondition. Only through improving their independent learning ability can they make independent study and complete knowledge internalization during communicating with students and teachers and turn the knowledge they have acquired into their own things and put into practice, reduce their reliance on teachers when learning and increasing the chances for communication in English. The core of FCM is to improve students' independent learning ability and achieve the goal of "teaching one to fish is better than giving him fish", which will be beneficial to students' future learning career.

\section{Flipped classroom can help teachers and students' flip and improve role center and improve teaching quality}

In traditional teaching model, classrooms is only the environment for teachers to instruct knowledge to students with the purpose of transmitting the max knowledge to students in limited time and space to achieve the optimal teaching effect. The purpose of traditional teaching model is about how to improve knowledge transmission effect but with no attention to students' subject of learning in the teaching work and no consideration of the individual difference between students including their receptivity and knowledge application ability, with no specific teaching based on students' characteristic so that the teaching quality cannot be improved. FCM uses the method of combining online knowledge transmission with individual guidance to help students gain knowledge absorption knowledge to be the subject in the learning process for individual learning and differentiated development, which does not exist in traditional teaching model.

When using FCM, it is necessary to pay attention that it is not video teaching as the most important thing of FCM is the process of knowledge internalization in class and students improve learning effect through communication with teachers and classmates, which is also the core of FCM. Even the teaching videos in flipped classrooms seem to replace teachers in traditional teaching models and teachers seem to play less roles, in the process of using FCM, roles of teachers and classmates are getting changed. In traditional teaching model, teacher's role is the saint in a high rack but in FCM teacher turns into the instructor beside students so that students can be freed from the limitation of traditional education to independently learn rather than to receive passively as the learning master truly. This learning objective can make teachers become the director of students' in their learning process. Therefore, in FCM, teachers never play less but larger role. Currently, in FCM, there are not enough training for students' listening and speaking training but teachers have the chance to make English oral communication with students by using FCM to truly achieve knowledge internalization. During the communication process, teachers can correct students' problems of oral English to improve their ability. In FCM, students will have more time to use English, which can guarantee students' interest in learning English and improving their confidence to speak English. 


\section{Specific measures to introducing FCM into college English teaching}

\section{Reposition the role of teacher and students}

Traditional teaching model sets teachers as the teaching center but the FCM sets students as the teaching center. Therefore, when using FCM, it is necessary to change the teaching center. Teachers should adjust their mindset and change concepts and truly achieve the teacher-student equality without being limited by hierarchy and not only playing the role of knowledge instructor rather than to be the role to solve puzzlement to help student truly independently study.

During the process of teacher's guiding students for study, they should fully know the practical condition of each students and their differences on learning ability and try to make one-to-one instruction so as to help students to obtain more knowledge within limited time and space and help them digest. FCM has set great requirement for teachers that they should have a detailed understanding of each student's learning condition with excellent guiding ability, professional ability and communication ability.

\section{Strengthen each student's independent learning ability}

FCM requires for students to study the teaching videos assigned by teaches and the quality of learning videos is also influencing the effect of knowledge internalization. The knowledge transmission in traditional teaching model is to transmit knowledge in single direction but in FCM the knowledge transmission is the reverse exploration of knowledge which will improve students' ability to better acquire knowledge and require them to increase self-learning ability with good initiative and self-discipline. Before class, students will adjust based on their own learning condition and choose suitable learning time and contents. At class, they will discuss with teachers to improve English level through interaction. If students improve their self-learning ability, they will benefit in their future academic study. Only through introducing FCM can college English teaching quality be greatly improved.

\section{Conclusion}

Flipped classroom teaching model is the innovative teaching model in information age, in accordance with Chinese educational reform tendency. Using FCM can compensate the defects in traditional teaching model, improve teaching quality of Chinese college English course and strengthen students' self-learning ability. Chinse college English teaching quality can be improved only through reform to strengthen college students' English level. Therefore, based on various advantages of flipped classroom teaching model, it is a foresighted choice to introduce FCM into college English teaching.

\section{Reference}

[1] Ma Mingshan, Qiao Dandan, Wang Xiangzheng. Course evaluation and enlightenment of Khan Academy in public view, China Educational Technology, 2014,(1):93-98.

[2] Song Yanling, Meng Zhaopeng, Yan Yajuan. Exploration of flipped classroom from the perspective of cognitive load-analysis on the typical model of flipped classroom, Distance Education Journal, 2014,(1):105-112. 